\title{
Utilização do ácido peracético na desinfecção de esgoto sanitário: uma revisão
}

\section{Use of peracetic acid in disinfection of wastewater: a review}

\author{
Grasiele Soares Cavallini'; Sandro Xavier de Campos²; Jeanette Beber de Souza3; \\ Carlos Magno de Souza Vidal ${ }^{4}$
}

\section{Resumo}

A utilização do Ácido Peracético (APA) na desinfecção de esgoto sanitário vem sendo pesquisada por diversos autores, principalmente em países europeus, onde os padrões microbiológicos para lançamento de efluentes em corpos hídricos são mais rigorosos e a moderação no uso do cloro, devido à formação dos trihalometanos, é recomendada. Nesta perspectiva, este trabalho apresenta uma compilação de pesquisas aplicadas diretamente ao saneamento ambiental, como também de pesquisas relacionadas às características químicas do APA e seus mecanismos de reação. A combinação destas informações fornece uma visão teórica e prática da utilização deste oxidante, a qual contribui para a continuidade de pesquisas nesta área, visando benefícios ambientais, econômicos e de saúde pública.

Palavras-chave: Ácido peracético. Desinfecção de esgoto sanitário. Características químicas do APA.

\begin{abstract}
The use of peracetic acid (PAA) to disinfect the wastewater has been researched for diverse authors, mainly in European countries, where the microbiological standards to release the effluents in water bodies are more severe and the moderation to use chlorine, due to the raising of trihalometanos is recommended. In this perspective, this work presents a compilation of researches applied directly to environmental sanitation, as well as the researches related to chemical characteristics of PAA and its reaction mechanisms. The combination of this information gives a theoretical and practical view of the use of this oxidant, which contributes to continue the researches in this area, aiming to benefit the environment, economy and public health system.
\end{abstract}

Key words: Peracetic acid. Disinfection wastewater. Chemical characteristics of the PAA.

\footnotetext{
${ }^{1}$ Graduada e mestre em Química, Universidade Estadual de Ponta Grossa; grasiele@irati.unicentro.com.br .

2 Docente do Departamento de Química da Universidade Estadual de Ponta Grossa; campos@uepg.br .

${ }^{3}$ Docente do Departamento de Engenharia Ambiental da Universidade Estadual do Centro-Oeste; jeanette@irati.unicentro.br .

${ }^{4}$ Docente do Departamento de Engenharia Ambiental da Universidade Estadual do Centro-Oeste; cacavidal@yahoo.com.br .
} 


\section{Introdução}

Todos os anos as companhias de saneamento objetivam aumentar sua área de atendimento, na busca da totalidade quanto à distribuição de água e coleta de esgoto, porém a disparidade econômica regional, a densidade demográfica e a extensão territorial do país dificultam esta tarefa, tornando constantes as doenças de veiculação hídrica no Brasil.

Neste contexto, pode-se imaginar que todo problema de saneamento estaria sendo solucionado à medida em que toda população fosse provida destes recursos. No entanto, a suposição de que o esgoto coletado e tratado deixa de ser um agente contaminante não é correta, isto porque, os efluentes finais das Estações de Tratamento de Esgoto (ETE) são potencialmente nocivos a saúde humana, uma vez que, os tratamentos convencionais não são suficientes para a inativação significativa de organismos patogênicos.

Por este motivo, a desinfecção de efluentes finais de ETE vem sendo cada vez mais utilizada, a fim de contribuir para qualidade do efluente final, visando benefícios ambientais, econômicos e de saúde pública.

Atualmente, a preocupação com a eficiência das ETE não se restringe as questões da saúde, mas também a promissora comercialização desse efluente. A proposta de reutilização vem sendo amplamente discutida e cada vez mais aceita (MACEDO et al., 2006). Neste sentido, se evidência um momento oportuno para propor novos métodos de desinfecção.

Um exemplo real deste reaproveitamento acontece em países como o Reino Unido e a Itália, onde as águas residuárias passam por um tratamento terciário, aplicando o ácido peracético (APA) e depois são utilizadas na agricultura. Nestes países a utilização de desinfetantes a base de cloro se tornam inviáveis, logo, que o nível máximo de trihalometanos na água para reuso é de $0,03 \mathrm{mg} / \mathrm{L}$ segundo a legislação local (NURIZZO et al., 2005;
FALSANISI et al., 2006; ROSSI et al., 2007; AZZELLINO et al., 2011).

A desinfecção com o cloro, certamente é a mais praticada, porém a formação de subprodutos potencialmente carcinogênicos como os trihalometanos, e os gastos com a descloração, incentivam a pesquisa de desinfetantes alternativos que substituam seu emprego.

A propriedade oxidante do APA torna-o um promissor substituinte, apresentando eficiência de inativação de E. coli, uma bactéria indicadora de contaminação, superior ao ozônio e a radiação ultravioleta (COSTA, 2007).

Nesta perspectiva, este trabalho objetiva reunir as informações pertinentes à utilização do APA como desinfetante de esgoto sanitário. Destacando que o APA, um oxidante amplamente utilizado em sínteses químicas, no branqueamento do papel, na medicina, na indústria alimentícia para limpeza de equipamentos, está sendo recentemente estudado na área de saneamento ambiental.

\section{Uso do APA na desinfecção de efluentes}

As propriedades desinfetantes do APA foram citadas pela primeira vez em 1902, por Freer e Novy, mas a disponibilidade comercial deste produto só foi possível após a fabricação do peróxido de hidrogênio $90 \%$, isso porque, o APA é produzido a partir da reação do ácido ou anidrido acético com peróxido de hidrogênio, na presença de ácido sulfúrico como catalisador (BLOCK, 2001).

Desde a década de quarenta, do século XX, as aplicações do APA vem sendo pesquisadas, e a partir disso, sua eficiência como bactericida, fungicida, esporicida e virucida tem sido relatada por diversos autores.

Segundo Kitis (2004), os pioneiros a pesquisar o APA como desinfetante no tratamento de efluentes foram Baldry e French (1989a), os quais descreveram a eficiência do APA relacionando o 
tempo de contato e a concentração do composto na inativação de coliformes. Posteriormente, ensaios em amostras artificiais foram realizados para testar a eficiência de inativação de bactérias e vírus tipicamente encontrados em esgoto, os quais comprovaram a eficiência do APA mesmo na presença de matéria orgânica (BALDRY; FRENCH, 1989b). Em 1995, pesquisas em grande escala feitas no Brasil e na Itália comprovaram que a aplicação do APA em países de clima tropical e temperado é recomendável, isso porque sua eficácia foi superior ao hipoclorito de sódio, atuando como controlador do cólera (BALDRY et al., 1995). Ainda na área ambiental Baldry et al. (1995) descreveu a utilização do APA na redução de patógenos em biossólidos.

Segundo Baldry, French, e Slater (1991) a maior importância da utilização do APA na desinfecção de efluentes é sua propriedade virucida, visto que, em relação ao hipoclorito de sódio a sua capacidade de inativação é menos afetada pela presença de matéria orgânica e permanece em atividade por mais tempo.

Aslari, Roques e Michel (1992) avaliaram a concentração bactericida mínima de quatro desinfetantes: APA, peróxido de hidrogênio, formaldeído e cloro. Com relação a inativação de E. coli em água o desempenho do APA não se apresentou dependente do tempo de contato, diferentemente dos outros desinfetantes. Com o cloro, por exemplo, obteve-se a concentração bactericida mínima de $6 \mathrm{mg} / \mathrm{L}$ para um tempo de contato de 5 minutos, aumentando o tempo de contato para 3 horas a concentração bactericida mínima decaiu para $0,048 \mathrm{mg} / \mathrm{L}$ de cloro. No caso do APA, a concentração bactericida mínima requerida de $3 \mathrm{mg} / \mathrm{L}$ foi a mesma em tempos de contato de 30 minutos até 7 horas, quando o teste foi finalizado.

Na Espanha, Sanchez-Ruiz, Martinez-Royano e Tejero-Monzon (1995) avaliaram a aplicação do APA na desinfecção de esgoto bruto para lançamento no oceano. Nesta pesquisa concluíram que as propriedades biocidas do APA variavam de acordo com quatro fatores: a natureza e concentração de matéria orgânica, a presença de sólidos suspensos, a concentração inicial de coliformes e principalmente pelo $\mathrm{pH}$, visto que, em meio alcalino a inativação foi menor que em condições de $\mathrm{pH}$ neutro ou ácido. Para o efluente em estudo a dosagem ótima foi de $20 \mathrm{mg} / \mathrm{L}$, com um tempo de contato de 10 minutos, a inativação dos microrganismos foi parcial devido ao teor de matéria orgânica. Em laboratório, os autores simularam o lançamento deste efluente tratado na água do mar, nestas circunstâncias observaram que houve um aumento da população de coliformes quando submetidos à escuridão, tal fato foi interpretado como uma recuperação das células danificadas, mas não destruídas, possibilitando sua replicação.

$\mathrm{Na}$ Finlândia, Rajala-Mustonen, Toivola e Heinonen-Tanski (1997) estudaram o APA combinado com a radiação ultravioleta na inativação de colifagos em esgoto, isto porque, embora a radiação UV se mostre mais eficiente que o APA, o tempo de retenção do efluente para desinfecção é muito longo, o que acaba inviabilizando o método. No entanto com a combinação dos dois desinfetantes o tempo de exposição à radiação UV foi reduzida e a inativação dos colifagos foi satisfatória.

Segundo Veschetti et al. (2003) em comparação com o hipoclorito de sódio o APA apresenta similar poder bactericida em relação aos microrganismos coliformes totais, coliformes fecais, E. coli, Salmonella sp. e Pseudomonas sp. Porém a concentração inicial de APA no esgoto deve ser cerca de três e oito vezes maior do que a concentração de hipoclorito de sódio para reduzir os microrganismos estreptococos fecais e bacteriófagos anti-E. coli, respectivamente, para $10 \%$ da população inicial. Outros microrganismos que apresentam certa resistência ao APA são os clostrídios (BALDRY et al., 1995), alguns vírus e parasitas como, oocistos de Cryptosporidium parvum e cistos de Giardia lamblia, apresentando eficiência reduzida, assim como a qualquer outro desinfetante químico, incluindo o cloro (LAZAROVA et al., 1998; GRASSO et al., 1996). 
Mais recentemente, outros autores também descreveram bons resultados de eficiência de desinfecção com a utilização do APA em estações de tratamento de esgoto.

Em 2005, Koivunem e Heinonen-Tanski, observaram que a eficiência na desinfecção com APA foi relativamente constante em efluentes secundário e terciário, por apresentarem características como DQO, turbidez e ST parecidos, porém, no efluente primário onde os teores de SST, matéria orgânica e microrganismos são mais elevados a eficiência de desinfecção decai claramente, confirmando os resultados de Sanchez-Ruiz, Martinez-Royano e Tejero-Monzon (1995).

Falsanisi et al. (2006) aplicaram o APAno efluente de uma ETE, da cidade de Taranto, localizada no sul da Itália, objetivando o reuso desse efluente na agricultura. Neste trabalho os pesquisadores investigaram a cinética do APA e a demanda do desinfetante conforme as condições do efluente, sendo aplicado tanto no efluente primário como no secundário. De acordo com o limite de E. coli permitido para reuso agrícola de efluentes na Itália, que é de $10 \mathrm{UFC} / 100 \mathrm{~mL}$, o efluente secundário teve como dosagem ótima $4 \mathrm{mg} / \mathrm{L}$ de APA em um tempo de contato de 10 minutos, enquanto o efluente primário demandou uma dosagem de 31 $\mathrm{mg} / \mathrm{L}$ e tempo de contato de 40 minutos, com esta comparação concluíram que os SST, a DQO e os metais presentes aumentaram significativamente o consumo do oxidante.

Rossi et al. (2007), na Itália, estudaram parâmetros parecidos a Falsanisi et al. (2006), identificando que a cinética de degradação do APA é relevante, por ele ser uma mistura em equilíbrio, o que leva a uma diminuição natural da concentração de APA disponível para a desinfecção. Na Itália, a obrigatoriedade da filtração e nitrificação tanto para as águas descartadas nos rios, quanto as destinadas ao reúso refletem em um efluente de boa qualidade, o que implica em doses comuns de desinfetante que variam de 1 a $3 \mathrm{mg} / \mathrm{L}$. O potencial de recrescimento da E. coli foi analisado após a aplicação do APA e satisfatoriamente o desinfetante não ofereceu condições de restabelecimento do microrganismo.

No Brasil, a utilização do APA como desinfetante e esterilizante foi concedida pela Agência Nacional de Vigilância Sanitária (ANVISA), em 29 de novembro de 1993, através da portaria $n^{\circ} 122 / \mathrm{DTN}$, sendo incluída à Portaria $\mathrm{n}^{\circ} 15$, de 23 de agosto de 1988, a qual regulamenta o registro de produtos domissanitários com finalidade antimicrobiana, porém, a desinfecção de água de abastecimento ainda é feita através do cloro.

Sartori (2004) avaliou a inativação de E. coli, colifagos e C. perfringens pelos desinfetantes ozônio, permanganato de potássio e APA em efluente secundário de esgoto sanitário, observando que o APA apresentou maior poder bactericida em relação ao ozônio e o permanganato de potássio.

Souza (2006) comparou métodos de desinfecção utilizando cloro, APA, ozônio e o processo combinado cloro/ozônio em água. Neste trabalho o APA indicou inativação efetiva dos microrganismos E. coli, colifagos e C. perfringens, mesmo em presença elevada de matéria orgânica.

Shikishima, Ribeiro e Kunigk (2008) estudaram a influência da salinidade e da temperatura na cinética de decomposição de soluções de APA. Neste estudo concluíram que em temperaturas específicas, quanto maior a salinidade, maior a velocidade de decomposição do APA, sendo esta uma reação de decomposição de primeira ordem.

Cavallini (2011) utilizou APA $10 \mathrm{mg} / \mathrm{L}$ na desinfecção de efluente secundário de ETE e obteve emmédia4 logs de inativação para os microrganismos coliformes totais e E. coli, com tempo de contato de 20 minutos. Além da desinfecção foi observado um aumento de $60 \%$ do oxigênio dissolvido no efluente. 
Obtenção e Mecanismos de reação do APA

Deacordo com suas propriedades físico-químicas, o APA apresenta-se mais eficiente na inativação de bactérias, seguido de vírus, esporos bacterianos e protozoários (LIBERTI; NOTARNICOLA, 1999).

O mecanismo de ação do APA é descrito por Jolivet-Gougeon et al. (1996) como um rompimento nas ligações sulfídricas e sulfúricas das enzimas que compõe a membrana celular, prejudicando atividades como: o transporte ativo através da membrana e os níveis de soluto dentro das células.

O APA é uma mistura quaternária em equilíbrio, formada por ácido peracético, peróxido de hidrogênio, ácido acético e água.

Segundo Zhao et al. (2007) o APA pode ser preparado de duas maneiras, pelo peróxido de hidrogênio ou pela oxidação de acetaldeído, sendo este último realizado tanto na fase líquida quanto na fase de vapor. Por muitos anos o método mais utilizado para a preparação do APA tem sido através da combinação do peróxido de hidrogênio com o ácido acético (1) ou anidrido acético (2).

$\mathrm{CH}_{3} \mathrm{COOH}+\mathrm{H}_{2} \mathrm{O}_{2} \stackrel{\mathrm{H} 2 \mathrm{SO} 4}{\leftrightarrow} \mathrm{CH}_{3} \mathrm{COOOH}+\mathrm{H}_{2} \mathrm{O}$

$\left(\mathrm{CH}_{3} \mathrm{CO}\right)_{2} \mathrm{O}+2 \mathrm{H}_{2} \mathrm{O}_{2} \leftrightarrow 2 \mathrm{H}_{3} \mathrm{CO} 4 \mathrm{COOH}+\mathrm{H}_{2} \mathrm{O}$

A reação do anidrido acético com o peróxido de hidrogênio é exotérmica e de difícil controle, possibilitando a formação de peróxido de diacetil que eleva os riscos de explosão. Sendo assim, a reação entre o ácido acético e o peróxido de hidrogênio é mais comum, pois é uma reação reversível e, assim, uma mistura em equilíbrio é obtida. O nível em que o equilíbrio é alcançado pode ser catalisado pela adição de um ácido forte, normalmente o ácido sulfúrico. A etapa determinante na síntese do APA é a reação entre o peróxido de hidrogênio com o intermediário ativo correspondente a carbonila, e na hidrólise, a reação entre a água e intermediário ativo carbonila, sendo ambas as reações de primeira ordem (Figura 1). As energias de ativação correspondentes a síntese e a hidrólise são de $57,8 \mathrm{~kJ} \cdot \mathrm{mol}^{-1}$ e 60,4 $\mathrm{kJ} . \mathrm{mol}^{-1}$, respectivamente.

Figura 1- Mecanismos de reação com catalisador ácido: (a) síntese e (b) hidrólise do APA.
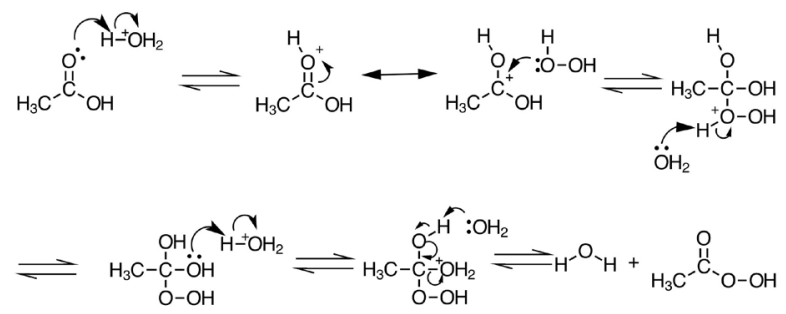

(a)
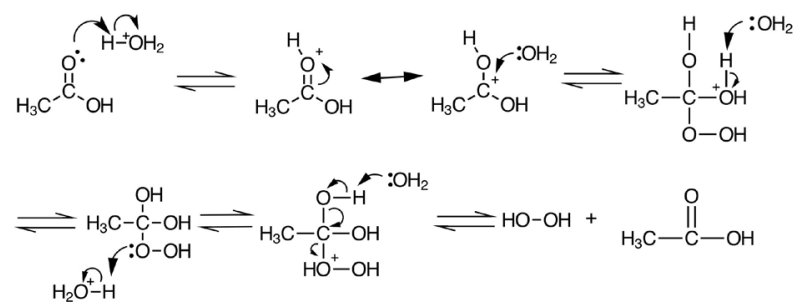

Fonte: Zhao et al. (2008).

Comercialmente o APA é encontrado nas concentrações de 5\%,15\% e 45\% (m/v), porém acima de $15 \%$ apresenta risco de explosão devido a sua instabilidade e reatividade, tornandose mais conveniente sua comercialização em concentrações mais baixas e com quantidades maiores de estabilizantes como o agente quelante 8-hidroxiquinolina e o agente sequestrante pirofosfato de sódio, que removem traços de metais que aceleram a decomposição de peróxidos (BLOCK, 2001; SANTORO et al., 2007). A Tabela 1 apresenta as características físico-químicas do APA na sua forma comercial de $15 \%$. 
Tabela 1 - Características físico-químicas do APA $15 \%$.

Composição: $15 \%$ ácido peracético $\left(\mathrm{CH}_{3} \mathrm{COOOH}\right)$; $23 \%$ peróxido de hidrogênio (H2O2), 16\% ácido acético $\left(\mathrm{CH}_{3} \mathrm{COOH}\right)$

Massa Molar: 76,05 g/mol

Aparência: Líquido incolor

Odor: Pungente

Densidade a $20^{\circ} \mathrm{C}: 1,148 \mathrm{~g} / \mathrm{cm}^{3}$

Temperatura de Decomposição: $55^{\circ} \mathrm{C}$

Pressão de vapor $20^{\circ} \mathrm{C}: 25 \mathrm{Mbar}$

$\mathrm{pH} 100 \mathrm{~g} / \mathrm{L} \mathrm{H} 2 \mathrm{O} 20^{\circ} \mathrm{C}: \sim 2$

Ponto de Ebulição: Não aplicável (decomposição)

Ponto de congelamento: $-50^{\circ} \mathrm{C}$

Ponto de fulgor DIN 51584: $96^{\circ} \mathrm{C}$

Temperatura de ignição DIN $1794: 265^{\circ} \mathrm{C}$

Propriedade: Oxidante

Solubilidade: Em água e solventes orgânicos (ácido acético, acetato de etila, clorofórmio, acetona, benzeno, dicloroetano, dicloroetileno)

Compatibilidade: Aço inox (304, 316, 316L), alumínio puro, vidro, porcelana, borrachas butílica e nitrílica, PVC, PE, PP, TEFLON ${ }^{\circledR}$, VITON ${ }$, KALREZ®

Incompatibilidade: Metais: ferro, cobre, níquel, titânio, manganês, cromo, chumbo, ouro, prata, alumínio impuro e respectivas ligas

Reativo com: Ácidos sulfúrico e clorídrico, hidróxido de sódio, barrilha $\left(\mathrm{Na}_{2} \mathrm{SO}_{3}\right)$, ferro, cobre, permanganato de potássio, bissulfito de sódio, etanol e gasolina

Estabilidade: Evitar calor

Perigos: Pode ser fatal se inalado ou absorvido pela

pele. Causa queimaduras graves em contato com os olhos, pele e mucosas.

Manuseio: Usar equipamentos de proteção adequados (luvas, óculos de proteção)

Fonte: SOLVAY

O caráter explosivo do APA se dá pela presença do radical peróxido, isso porque, a ligação oxigêniooxigênio é fraca, podendo ser quebrada pela energia derivada de um choque mecânico, calor, luz ou contato químico. Os radicais livres formados na quebra da ligação $\mathrm{O}-\mathrm{O}$, são altamente reativos e liberam grande quantidade de energia durante a decomposição da substância, por isso, consideradas termodinamicamente instáveis.

O APA é considerado um peróxido orgânico, sendo assim o risco a saúde atribuído ao APA $12 \%$ é semelhante ao do peróxido de hidrogênio $50 \%$ (KITIS, 2004), isto porque, a energia para a quebra da ligação O-O do peróxido de hidrogênio é relativamente elevada (51 kcal.mol-1), necessitando de uma temperatura acima de $120^{\circ} \mathrm{C}$ para sua ruptura homolítica, o que torna o peróxido de hidrogênio mais estável que o APA (KADLA, 2001 apud ZHAO et al., 2008).

O grupo funcional do APA é classificado como ácido percarboxílico, e de acordo com Brasileiro et al. (2001) os perácidos em solução são mais voláteis e menos ácidos do que os ácidos carboxílicos correspondentes. $\mathrm{O} \mathrm{pK}_{\mathrm{a}}$ do ácido peracético é 8,2, enquanto o pKa do ácido acético é 4,76. Isto ocorre, porque o perácido tende a formar uma ligação de hidrogênio intramolecular, reduzindo o efeito indutivo do grupo acila sobre o próton devido à introdução de um segundo átomo de oxigênio, como se observa na Figura 2.

Figura 2 - Possível estrutura do APA

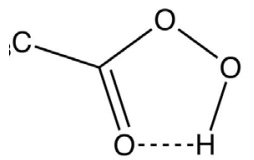

Fonte: (ANDO et al., 1992 apud BRASILEIRO et al., 2001).

\section{Cinética de Decomposição do APA}

Uma solução de APA 1\% perde metade de sua potencialidade em 6 dias devido a sua hidrólise (ROSSI et al., 2007). Em efluentes contaminados por metais a decomposição do APA é catalisada, por este motivo, agentes complexantes são muitas vezes adicionados para impedir as reações 
entre peróxidos e íons metálicos, sendo o ácido dietilenotriaminopentacético (DTPA) um dos mais eficazes complexantes para reduzir os íons metálicos livres e amenizar a decomposição do oxidante, que ocorre em condições de $\mathrm{pH}$ neutro ou alcalino. Porém, a utilização do DTPA aumenta os custos da aplicação do APA e, segundo Zhao et al. (2008), em meio fortemente ácido este complexante pode ser oxidado pelo APA levando a um consumo adicional do oxidante, ou ainda estimular a hidrólise do APA para formar peróxido de hidrogênio.

A eficiência de desinfecção do APA pode variar conforme o tempo de contato, a temperatura, o $\mathrm{pH}$, o teor de matéria orgânica e de sólidos e o potencial de oxidação do APA (SANCHEZ-RUIZ; MARTINEZ-ROYANO; TEJERO-MONZON, 1995; LAZAROVA et al., 1998; FALSANISI et al., 2008). O potencial deste oxidante pode ser comparado com outros desinfetantes de uso cotidiano conforme descrito na Tabela 2.

Tabela 2 - Potenciais de redução de alguns oxidantes.

\begin{tabular}{lc}
\hline Semirreações & $e 0, \mathrm{~V}$ \\
\hline $\mathrm{O} 3+2 \mathrm{H}^{+}+2 \mathrm{e}^{-} \rightarrow \mathrm{O}_{2}+\mathrm{H}_{2} \mathrm{O}$ & 2,07 \\
\hline $\mathrm{H}_{2} \mathrm{O}_{2}+2 \mathrm{H}_{+}+2 \mathrm{e}^{-} \rightarrow 2 \mathrm{H}_{2} \mathrm{O}$ & 1,78 \\
\hline $\mathrm{HClO}_{2}+3 \mathrm{H}^{+}+4 \mathrm{e}^{-} \rightarrow \mathrm{Cl}^{-}+2 \mathrm{H}_{2} \mathrm{O}$ & 1,56 \\
\hline $\mathrm{HOCl}^{+} \mathrm{H}^{+}+2 \mathrm{e}^{-} \rightarrow \mathrm{Cl}^{-}+\mathrm{H}_{2} \mathrm{O}$ & 1,49 \\
\hline $\mathrm{HSO}_{5}^{-}+2 \mathrm{H}^{+}+2 \mathrm{e}^{-} \rightarrow \mathrm{HSO}_{4}^{-}+\mathrm{H}_{2} \mathrm{O}$ & 1,44 \\
\hline $\mathrm{Cl}_{2}+2 \mathrm{e}^{-} \rightarrow 2 \mathrm{Cl}^{-}$ & 1,36 \\
\hline $\mathrm{ClO}_{2}+\mathrm{H}^{+}+\mathrm{e}^{-} \rightarrow \mathrm{HClO}_{2}$ & 1,15 \\
\hline $\mathrm{CH}_{3} \mathrm{CO}_{3} \mathrm{H}+2 \mathrm{H}^{+}+2 \mathrm{e}^{-} \rightarrow \mathrm{CH}_{3} \mathrm{CO}_{2} \mathrm{H}+\mathrm{H}_{2} \mathrm{O}$ & 1,06 \\
\hline $\mathrm{ClO}^{-}+\mathrm{H}_{2} \mathrm{O}+2 \mathrm{e}^{-} \rightarrow \mathrm{Cl}^{-}+2 \mathrm{OH}^{-}$ & 0,90 \\
\hline $\mathrm{HOO}^{-}+\mathrm{H}_{2} \mathrm{O}+2 \mathrm{e}^{-} \rightarrow 3 \mathrm{OH}^{-}$ & 0,87 \\
\hline $\mathrm{ClO}_{2}^{-}+2 \mathrm{H}_{2} \mathrm{O}+4 \mathrm{e}^{-} \rightarrow \mathrm{Cl}^{-}+4 \mathrm{OH}^{-}$ & 0,78 \\
\hline $\mathrm{O}_{2}+2 \mathrm{H}_{2} \mathrm{O}+4 \mathrm{e}^{-} \rightarrow 4 \mathrm{OH}^{-}$ & 0,40 \\
\hline
\end{tabular}

Fonte: BRASILEIRO et al. (2001).
De acordo com a composição do APA, na forma comercial, o peróxido de hidrogênio e o ácido acético presentes no produto reforçam a sua ação desinfetante, entretanto, o APA é mais potente que o peróxido, agindo contra uma gama maior de microrganismos de forma mais rápida e em concentrações mais baixas (WAGNER: BRUMELIS; GEHR, 2002).

O APA apresenta maior solubilidade em água e solventes orgânicos polares. $\mathrm{Na}$ faixa de $\mathrm{pH}$ entre 5,5 a 8,2 a decomposição do APA acontece espontaneamente, formando ácido acético e oxigênio (GEHR et al., 2002 apud KITIS, 2004).

Koubec (1964 apud ZHAO et al., 2008) descreve a reação de decomposição espontânea do APA na faixa de $\mathrm{pH}$ entre 5,9 a 10,2, observando que a cinética dessa reação é de segunda ordem, conforme a Figura 3.

Figura 3 - Decomposição espontânea do APA

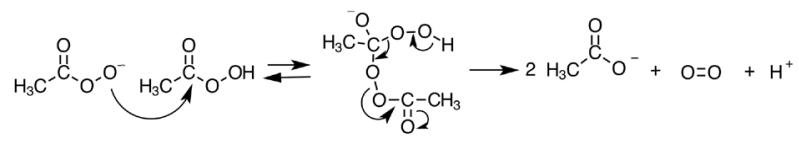
Fonte: (KOUBEC, 1964 apud ZHAO et al., 2008).

Zhao et al. (2008) observaram que os modelos de dados calculados por Koubec et al. (1963 apud ZHAO et al., 2008) e Yuan et al. (1997 apud ZHAO et al., 2008) foram muito menores do que seus respectivos dados experimentais, isso porque, a reação em uma condição de ácido forte segue um mecanismo de reação diferente, o que resulta em um comportamento cinético diferente de decomposição do APA. Como na preparação do APA, a concentração de $\mathrm{H}+$ no sistema é geralmente maior do que 0,1 mol.L ${ }^{-1}$, o APA está presente na solução na forma molecular e não como ânion perácido. Neste caso, Zhao et al. (2008) observaram 
que o ácido sulfúrico tem um efeito positivo sobre redução na decomposição do APA, indicando que o $\mathrm{H}+$ participa da reação não só como um catalisador. Assim, propôs que a reação consiste principalmente de três etapas: protonação do átomo de oxigênio (Figura 4), a formação do intermediário e formação dos produtos finais.

Figura 4 - Etapa 1: Protonação do átomo de oxigênio na molécula de APA. (E) molécula de APA

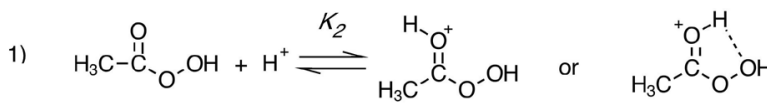

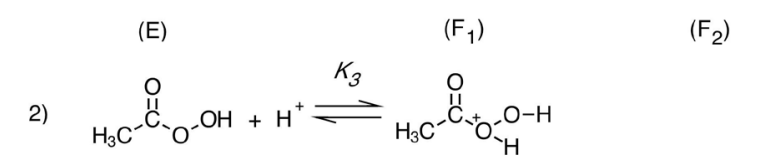$$
\text { (E) (G) }
$$

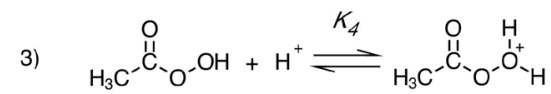

$\left(\mathrm{K}_{2}, \mathrm{~K}_{3}\right.$ e $\left.\mathrm{K}_{4}\right)$ correspondentes constantes de equilíbrio

Fonte: (ZHAO et al., 2008).

Portanto, três isômeros (denotados como F1/F2, $\mathrm{G}$ e I, respectivamente) podem ser formados pela protonação do átomo de oxigênio correspondente.

Segundo Shi et al. (2005 apud ZHAO et al., 2008), a primeira reação é a mais provável uma vez que há maior carga negativa no átomo de oxigênio da carbonila, como mostrado na Figura 5 (a).

Figura 5 - Distribuição de cargas na molécula de APA (a) e na molécula de APA protonada (b).

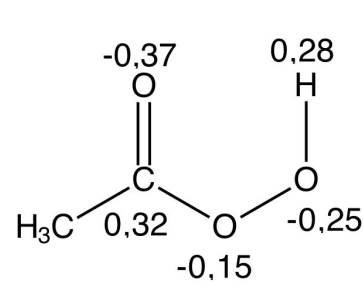

(a)

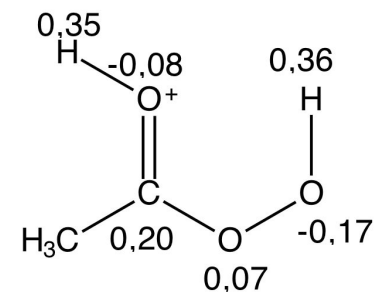

(b)
Figura 6 - Efeito de ressonância de elétrons entre os isômeros F1/F2 e J

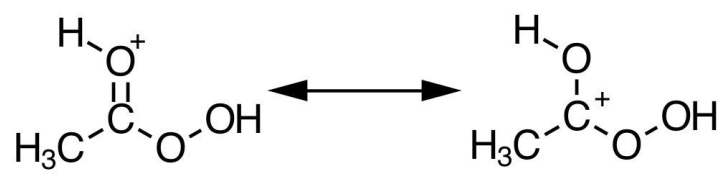

Fonte: (ZHAO et al., 2008).

$\mathrm{Na}$ segunda etapa, o carbono carbonílico ativo é atacado por um agente nucleofílico para formar um intermediário ativo. Após uma protonação, a carga negativa sobre os átomos de oxigênio é reduzida, como mostrado na Figura 5 (b). Sendo assim, o caminho mais provável é que o átomo de oxigênio da hidroxila, na molécula de APA, ataque a carbonila ativa e forme um intermediário ativo (Figura 7).

Figura 7 - Etapa 2: formação de um intermediário ativo.

(E)

(J)

(L)

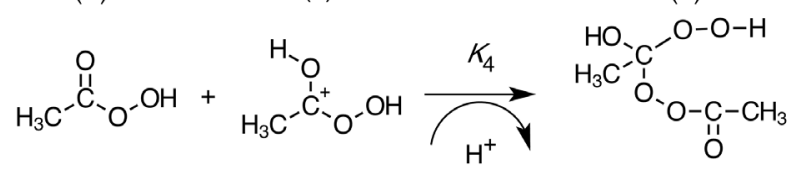

Fonte: (ZHAO et al., 2008).

$\mathrm{Na}$ última etapa, o intermediário instável (L) decompõe-se rapidamente a ácido acético e oxigênio (Figura 8).

Fonte: (ZHAO et al., 2008). 
Figura 8 - Etapa 3: formação do produto final.

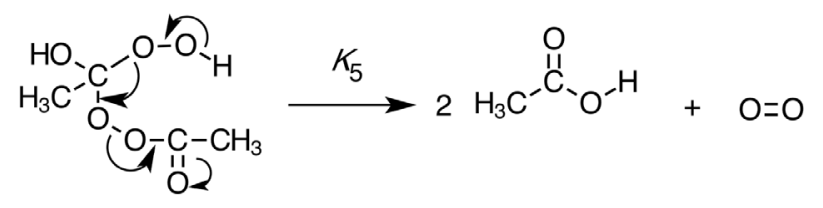

Fonte: (ZHAO et al., 2008).

O peróxido de hidrogênio também pode atuar como um agente nucleofílico e atacar o isômero (J). No entanto, o sistema $p-\pi$ conjugado do grupo acetil da molécula de APA pode fazer o átomo de oxigênio da hidroxila atrair mais carga negativa a partir do átomo de hidrogênio por um efeito de indução. Portanto, a molécula de APA é mais nucleofílica do que a molécula de peróxido de hidrogênio, e a reação da Figura 8 é a mais provável.

\section{Determinação de APA Residual}

Após a desinfecção de efluentes, a determinação do desinfetante residual é necessária, isto porque, a toxicidade do oxidante (APA e peróxido de hidrogênio), proporcionalmente a sua concentração, pode afetar a fauna e a flora aquática e também potencializar a formação de subprodutos. No caso do APA, a determinação do residual deve ser feita considerando os dois oxidantes que fazem parte da sua composição, uma vez que se trata de uma mistura em equilíbrio.

Os métodos mais utilizados para determinação do APA e do peróxido de hidrogênio envolvem a titulometria redox, sendo eles a iodometria, a cerimetria e a permanganometria. Em alguns casos, são utilizados de forma combinada entre eles.

D’Ans e Freyl (1912 apud Dudley e Williams, 1962) desenvolveram o método que utiliza a permanganometria para mensuração do peróxido, combinado com a iodometria para determinação do perácido. Mais tarde, Greenspan e Mckellar (1948 apud Dudley e Williams, 1962) modificaram o método substituindo a permanganometria pela cerimetria combinada com a iodometria (DUDLEY; WILLIAMS, 1962).

As metodologias propostas no passado continuam sendo aplicadas, segundo Zhao et al. (2008) os chineses utilizam o método permanganométrico em conjunto com a iodometria, semelhante ao proposto por D’Ans e Freyl (1912 apud Dudley e Williams, 1962). A fabricante do APA no Brasil sugere além do método permanganométrico/iodométrico, o método cerimétrico combinado com a iodometria (SOLVAY).

Dudley e Williams (1962) utilizaram apenas a iodometria para determinar os dois oxidantes, aproveitando a grande diferença em suas taxas de reação com iodeto, uma vez que o peróxido de hidrogênio reage com o iodeto muito lentamente, necessitando do íon molibdato como catalisador. Esta metodologia ainda é utilizada, sendo citada recentemente por Falsanisi et al. (2006), porém com a adição da catalase. A iodometria é um método mais simples, por ser aplicável em sistemas com $\mathrm{pH}$ entre 4-7, pois o equilíbrio entre o APA e o peróxido de hidrogênio não são significantes. Ao contrário da cerimetria e da permanganometria que exigem meios fortemente ácidos, em faixas de $\mathrm{pH}$ entre 3-5, para que não haja a mudança da composição da solução durante a determinação (VOGEL, 2008).

Baldry e Fraser (1988) indicam o método cerimétrico combinado com o iodométrico para amostras com concentrações acima de $150 \mathrm{~g} / \mathrm{kg}$ de peróxido de hidrogênio e $400 \mathrm{~g} / \mathrm{L}$ de APA.

Uma metodologia mais atual utiliza a espectrofotometria no vísivel, neste método, o peróxido de hidrogênio é consumido pela catalase, e apenas o APA é determinado. A determinação do APA se dá pela interação do perácido com o DPD (N,N-dietil-p-fenilenodiamina), a qual produz uma coloração avermelhada na amostra.

A reação ocorre pelo pré-tratamento da amostra com uma solução tampão de fosfato $(\mathrm{pH}=6,5)$ contendo iodeto de potássio em excesso. O iodeto 
de potássio é oxidado pelo APA liberando iodo, o qual oxida o DPD. Outros agentes oxidantes como halogênios, íons ferro (férrico) e cobre (cúprico) também produzem cor com o DPD. Um cromóforo parecido é comumente utilizado em kits comerciais na forma de ampola, o DDPD uma forma de metil substituída do reagente DPD (CHEMetrics ${ }^{\circledR}$ ), segundo FALSANISI et al. (2008) este kit não pode ser utilizado para determinação de APA em amostras de esgoto.

O método espectrofotométrico também pode ser desenvolvido através da interação do APA com o ABTS (2,2'-azino-bis-(3-etilbenzotiazolina)6-sulfonato) catalisado pela peroxidase HPR (horseradish peroxidade) proposto por Pütter e Becker (1983 apud WAGNER; BRUMELIS; GEHR, 2002). Neste método o APA e o peróxido de hidrogênio podem ser determinados, logo que, as duas espécies podem oxidar o ABTS a ABTS+, o qual é detectado pelo equipamento.

Baldry e Fraser (1988) adicionavam íons $\mathrm{Fe}^{2+}$ na amostra, o qual, em meio ácido, eram oxidados à $\mathrm{Fe}^{3+}$ pelo APA e pelo peróxido de hidrogênio, a adição de íons tiocianato produziam um complexo vermelho de tiocianato férrico, detectado por espectrofotometria em $460 \mathrm{~nm}$.

A limitação dos métodos espectrofotométricos está na distinção dos oxidantes, esse inconveniente pode ser amenizado adicionando o tiossulfato de sódio para o consumo do APA e então o peróxido de hidrogênio pode ser determinado, ou ainda, determina-se somente o APA com a adição da catalase que decompõe o peróxido de hidrogênio. Porém em ambos os casos a concentração final pode ser superestimada se o oxidante a ser neutralizado não for consumido totalmente, ou subestimando, como no caso da catalase que pode decompor parte do APA (WAGNER; BRUMELIS; GEHR, 2002; SHIKISHIMA, 2008). Outra possível explicação quanto ao consumo do APA durante a utilização da catalase é deslocamento químico da reação, por se tratar de uma reação em equilíbrio.
Cavallini (2011) comparou os métodos: cerimétrico/ iodométrico, permanganométrico/ iodométrico, iodométrico com catalase e DPD com catalase e observou que para determinação de APA entre 1 a $10 \mathrm{mg} / \mathrm{L}$ em esgoto sanitário, os melhores métodos são o cerimétrico/ iodométrico e DPD com catalase, sendo que para concentrações até $0,5 \mathrm{mg} / \mathrm{L}$ de APA apenas o último método foi satisfatório.

Sartori (2004) testou a metodologia proposta por Minning et al (1999 apud SARTORI, 2004) a qual utiliza o iodeto de potássio como cromóforo e medidas espectrofotométricas no comprimento de onda de $410 \mathrm{~nm}$ para determinação do APA, porém não obteve reprodutibilidade do método. Nesta metodologia considera-se que a cada miligrama de APA consumido são formados 3,4 mg de iodo, porém a inibição do interferente peróxido de hidrogênio não é comentada pela autora.

Embora vários métodos para determinação do APA sejam citados na literatura, estudos comparativos entre eles em uma mesma amostra não foram encontrados.

\section{Subprodutos formados na desinfecção utilizando o APA}

Em estações de tratamento de esgoto a aplicação do APA contribui de forma positiva, aumentado a oxigenação do efluente final. No entanto, a formação de ácidos carboxílicos pode aumentar a quantidade de material orgânico, incluindo o ácido acético, que por ser biodegradável acaba servindo de alimento para as bactérias decompositores podendo contribuir para o recrescimento microbiano (LAZAROVA et al., 1998) ou ainda promover a formação de possíveis subprodutos dependendo da composição do efluente.

Ensaios de toxicidade em ratos utilizando uma solução de APA 40\% indicaram que a dose letal suficiente para matar $50 \%$ dos ratos estudados $\left(\mathrm{DL}_{50}\right)$ é de $1540 \mathrm{mg} / \mathrm{kg}$, utilizando soluções menos concentradas de APA (4\%) a DL50 passa a $3400 \mathrm{mg} /$ 
kg. Em testes com suínos foi observado que soluções de $0,4 \%$ a $0,8 \%$ podem ser utilizadas diretamente na pele desses animais como desinfetante. O APA é considerado um carcinógeno fraco, porém, pode ser um potencial causador de tumores, sendo que em testes com animais, soluções de $2 \%$ provocaram tumores cutâneos em 10\% dos indivíduos estudados em seis meses (BLOCK, 2001).

Em bioensaios de toxicidade que avaliaram o potencial tóxico do APA residual utilizado na desinfecção de esgoto doméstico, mostrou que o desinfetante APA apresentou toxicidade a todas as espécies testadas (Daphnia similis, Ceriodaphnia silvestrii, Chironomus xanthus, Danio rerio $e$ Allium cepa), exceto ao C. xanthus. Comparado com outros desinfetantes expostos ao mesmo teste pode-se observar a seguinte ordem decrescente de toxicidade: cloro $>$ ozônio $>$ APA $>$ radiação ultravioleta. Dependendo da composição do esgoto o APA residual apresentava maior toxicidade, o que dá indícios de uma formação de subprodutos que potencializavam sua toxicidade. Porém, quando o efluente não desinfetado apresentava toxicidade as espécies testadas a radiação ultravioleta mostrou-se mais tóxica que o APA (COSTA, 2007).

Os subprodutos formados após a aplicação dos desinfetantes é um assunto relevante nas pesquisas de novos métodos de desinfecção. O APA é visto como um oxidante que não agride o ambiente, contudo, alguns autores tentam se certificar desta afirmação antes de propor a substituição do cloro pelo APA.

Crebeli et al.(2005) observaram que a desinfecção de esgoto com doses moderadas de APA não levam à formação de uma quantidade significativa de subprodutos genotóxicos. No entanto, enfatizam que a composição química variável de águas residuárias exige um monitoramento de praxe quanto sua genotoxidade e toxidade para uma avaliação final da aplicabilidade do APA.

Na Inglaterra Booth e Lester (1995) estudaram a formação de subprodutos a partir da aplicação do
APA em esgoto, neste trabalho os autores partiram do princípio de que por processos convencionais de tratamento de águas residuárias, as substâncias orgânicas tais como aminoácidos, fenóis e hidrocarbonetos aromáticos continuam presentes no efluente. Como o fenol é um excelente aceitador de radicais livres, a produção de compostos halogenados é facilitada. Por este motivo, as amostras de esgoto foram enriquecidas por fenóis, cloreto de sódio e brometo de potássio, a fim de testar a interferência do APA na formação dos subprodutos halogenados. Como resultados observaram que o aparecimento de clorofenóis, independia da temperatura e do tempo de contato com o APA, porém a concentração de subprodutos foi influenciada pela dosagem do APA, pela quantidade de cloreto e a concentração de compostos orgânicos e minerais constituintes do efluente final. No entanto, o APA não foi capaz de oxidar cloreto a ácido hipocloroso, concluindose que a transformação de fenol para clorofenol ocorre através da geração de radicais livres provenientes de outros contaminantes orgânicos do efluente. Contudo, a formação de 2- e 4-bromofenol demonstrou que o potencial eletroquímico do APA é suficiente para oxidar brometo para ácido hipobromoso e posteriormente formar compostos orgânicos bromados.

Um estudo comparativo entre o hipoclorito de sódio e o APA relata que a utilização do APA na desinfecção de efluentes não contribui para formação de compostos orgânicos halogenados $(\mathrm{AOX})$, diferentemente do hipoclorito de sódio onde o cloro livre residual em contato com a matéria orgânica promove formação destes subprodutos (VESCHETTI et al., 2003).

Mais recentemente Dell'Erba et al. (2007) realizaram novos estudos em escala piloto com o mesmo efluente utilizado por Booth e Lester (1995), tentando detectar aldeídos e bromofenóis. Os autores observaram a presença de aldeídos em concentrações negligenciáveis, sendo que os bromofenóis só foram detectados em condições não usuais como pH 3,8-4,2. Mesmo assim os autores reforçaram 
a importância de continuar a investigação dos possíveis subprodutos provenientes da desinfecção de efluentes com APA.

Monarca et al. (2004) utilizaram cromatografia gasosa com espectrômetro de massa acoplado para identificar subprodutos de desinfecção de três oxidantes: APA, hipoclorito de sódio e dióxido de cloro (Tabela 3). Nurizzo et al. (2005) utilizaram a mesma técnica, para determinação de aldeídos (formaldeído e acetaldeído) e trihalometanos totais provenientes da pré-desinfecção de águas superficiais e residuárias com APA, contudo, não observaram formação significativa dos subprodutos.

Tabela 3 - Subprodutos de desinfecção utilizando hipoclorito de sódio, dióxido de cloro e APA

\begin{tabular}{|c|c|c|}
\hline $\mathrm{NaClO}$ & $\begin{array}{l}\text { Subprodutos } \\
\text { halogenados }\end{array}$ & $\begin{array}{l}\text { Bromofórmio } \\
\text { Ácido dicloroacético } \\
\text { Ácido dibromoacético } \\
\text { 5-metil-2-furancarboxialdeído } \\
\text { 3-acetil-dihidro }\end{array}$ \\
\hline & $\begin{array}{l}\text { Subprodutos } \\
\text { halogenados }\end{array}$ & $\begin{array}{l}\text { Bromofórmio } \\
\text { Ácido dibromoacético } \\
\text { 1,1-dibromopropanona } \\
\text { 4,4-dibromo-2-butanona e } \\
\text { bromotolueno ( } 2 \text { isômeros) } \\
\text { 1,4-diclorobenzeno }\end{array}$ \\
\hline $\mathrm{ClO}_{2}$ & $\begin{array}{l}\text { Subprodutos } \\
\text { não } \\
\text { halogenados }\end{array}$ & $\begin{array}{l}\text { Hexanal } \\
\text { Heptanal } \\
\text { Octanal } \\
\text { Nonanal } \\
\text { 2-furancarboxialdeído } \\
\text { 5-metil-2-furancarboxialdeído } \\
\text { Ácido decanóico } \\
\text { Ácido dodecanóico } \\
\text { butil acetato }\end{array}$ \\
\hline APA & $\begin{array}{l}\text { Subprodutos } \\
\text { não } \\
\text { halogenados }\end{array}$ & $\begin{array}{l}\text { Nonanal } \\
\text { Decanal } \\
\text { 1-metoxi-4-metilbenzeno }\end{array}$ \\
\hline
\end{tabular}

Fonte: MONARCA et al. (2004).
Cavallini (2011) não observou a formação dos subprodutos decanal, nonanal, clorofenóis e 1-metoxi-4-metilbenzeno na desinfecção de efluente secundário de ETE com APA $10 \mathrm{mg} / \mathrm{L}$.

Segundo Kitis (2004) a principal desvantagem da aplicação do APA para desinfecção de efluentes de ETE são os custos. Comparado com o hipoclorito de sódio o APA custa cinco vezes mais, isso devido à limitada produção mundial.

\section{Conclusões}

De acordo com a revisão realizada é possível concluir que: a ação desinfetante do APA ocorre mesmo na presença de matéria orgânica, porém, o aumento da DQO e dos sólidos em suspensão do efluente diminuem a eficiência de desinfecção do APA. Na desinfecção de esgoto sanitário o APA apresentou resultados de toxicidade e formação de subprodutos inferiores quando comparados com o cloro, o que pode ser atribuído a sua composição e rápida decomposição no efluente. Os bons resultados obtidos pelos vários autores citados justificam a continuidade de estudos que contribuam para a aplicação do APA em escala real no Brasil.

\section{Referências}

ASLARI, A.; ROQUES, C.; MICHEL, G. Bactericidal properties of peracetic acid and hydrogen peroxide, alone ande in combination, and chlorine and formaldehyde against bacterial water strains. Canadian Journal of Microbiology, Ottawa, v. 38, n. 7, p. 635-643, 1992.

AZZELLINO, A.; ANTONELLI, M.; CANZIANI, R.; MALPEI, F.; MARINETTI, M.; NURIZZO, C. Multivariate modelling of disinfection kinetics: a comparison among three different disinfectants. Desalination and Water Treatment, Hopkinton, v. 29, p. 128-139, 2011.

BALDRY, M. G. C.; CAVADORE, A.; FRENCH, M. S.; MASSA, G.; RODRIGUES, L. M.; SCHIRCH, P. F. T.; THREADGOLD, T. L. Effluent disinfection in warm climates with peracetic acid. Water Science and Technology, Oxford, v. 31, n. 5/6, p. 161-164, 1995. 
BALDRY, M. G. C.; FRASER, J. A. L. Disinfection with peroxygens. In: PAYNE, K. R. (Ed.). Industrial biocides. Nova York: John Wiley \& Sons, 1988. p. 91-116.

BALDRY, M. G. C.; FRENCH, M. S. Disinfection of sewage effluent with peracetic acid. Water Science and Technology, Oxford, v. 21, n. 3, p. 203-206, 1989a.

BALDRY, M. G. C.; FRENCH, M. S.; SLATER, D. The ativicty of peracetic acid on sewage indicator bacteria and viruses. Water Science and Technology, Oxford, v. 24, n. 2, p. 353-357, 1991.

BALDRY, M. G. C; FRENCH, M. S. Activity of peracetic acid against sewage indicator organisms. Water Science and Technology, Oxford, v. 21, p. 1747-1749, 1989b.

BLOCK, S. S. Disinfection, Sterilization, and Preservation. 5th ed. Philadelphia: Lippincott William \& Wilkins, 2001.

BOOTH, R. A.; LESTER, J. N. The potential formation of halogenated by-products during peracetic acid treatment of final sewage effluent. Water Science and Technology, Oxford, v. 29, n. 7, p. 1793-1801, 1995.

BRASILEIRO, L. B.; COLODETTE, J. L.; PILÓVELOSO, D. A utilização de perácidos na deslignificação e no branqueamento de polpas celulósicas. Química Nova, São Paulo, v. 24, n. 6, p. 819-829, 2001.

CAVALLINI, G. S. Estudo do ácido peracético na desinfecção de esgoto sanitário: influência das características físico-químicas do efluente, determinação de concentração residual e cinética de degradação. 2011. 88 p. Dissertação (Mestrado em Química Aplicada) - Universidade Estadual de Ponta Grossa. Ponta Grossa.

CHEMetrics ${ }^{\circledR}$. Métodos Analíticos. Precision Laboratories Ltda. Disponível em: $<$ www.precisionlabs. com.br/dwn /metodologia_kits_chemetrics.pdf $>$. Acessado em: 17 mar. 2011.

COSTA, J. B. Avaliação ecotoxicológica de efluente de tratamento secundário de esgoto sanitário após desinfecção com ácido peracético, cloro, ozônio, radiação ultravioleta. 2007. 178 p. Tese (Doutorado em Ciências da Engenharia Ambiental) - Escola de Engenharia de São Carlos, Universidade de São Paulo, São Carlos.

CREBELLI, R.; CONTI, L.; MONARCA, D.; FERETTI, D.; ZERBINI, I.; ZANI, E. V.; CUTILLI, D.; OTTAVIANI, M. Genotoxicity of the disinfection byproducts resulting from peracetic acid- or hypochloritedisinfected sewage wastewater. Water Research, Oxford, n. 39, n. 6 , p. 1105-1113, 2005.

DELL'ERBA, A.; FALSANISI, D.; LIBERTI, L.; NOTARNICOLA, M.; SANTORO, D. Disinfection by- products formation during wastewater disinfection with peracetic acid. Desalination, Amsterdam, n. 215, p. 177186, 2007.

DUDLEY, B. S.; WILLIAMS, P. L. The analysis of solutions of per-acids and hydrogen peroxide. Research Laboratory, London, v. 87, p. 653-657, 1962.

FALSANISI, D.; GEHR, R.; LIBERTI, L.; NOTARNICOLA, M. Effect of suspended particles on disinfection of a physicochemical municipal wastewater with peracetic acid. Water Quality Research Journal of Canada, Burlington, v. 43, n. 1, p. 47-54, 2008.

FALSANISI, D.; GEHR, R.; SANTORO, D.; DELL'ERBA, A.; NOTARNICOLA, M.; LIBERTI, L. Kinetics of PAA demand and its implications on disinfection of wastewaters. Water Quality Research Journal of Canada, Burlington, v. 41, n. 4, p. 398-409, 2006.

GRASSO, D. (et al.). Wastewater Disinfection. Manual of Practice FD-10. Water Environment Federation. USA. 1996.

JOLIVET-GOUGEON, A.; BRAUX, A. S.; SAUVAGER, F.; ARTURO-SCHAAN, M.; CORMIER, M. Influence of peracetic acid on Escherichia coli H10407 strain in laboratory microcosms. Canadian Journal of Microbiology, Ottawa, v. 42, n. 1, p. 60-65, 1996.

KITIS, M. Disinfection of wastewater with peracetic acid: a review. Environment International, New York, v. 30, n. 1, p. 47-55, 2004.

KOIVUNEM, J.; HEINONEN-TANSKI, H. Peracetic acid (PAA) disinfection of primary, secondary and tertiary treated municipal wastewaters. Water Research, New York, v. 39, n. 18, p. 4445-4453, 2005.

LAZAROVA, V.; JANEX, M. L.; FIKSDAL, L.; OBERG, C.; BARCINA, I. Pommepuy M. Advanced wastewater disinfection technologies: short and long term efficiency. Water Science and Technology, Oxford, v. 38, n. 12, p. 109-117, 1998.

LIBERTI, L.; NOTARNICOLA, M.; Advanced treatment and disinfection for municipal wastewater reuse in agriculture. Water Science and Technology, Oxford, v. 40, p. 235-245, 1999.

MACEDO, L. C.; PAULI, E. D.; MANECHINI, B. P.; ZAIA, D. A. M.; SANTADA, H. Remediação de águas residuais por Fotocatálise Heterogênea: estudo dos parâmetros experimentais aplicados a fotocatálise eletroquímica. Semina: Ciências Exatas e Tecnológicas, Londrina, v. 27, n. 1, p. 11-21, 2006. 
MONARCA, S.; ZANI, C.; RICHARDSON, S.; THRUSTON, A. D.; MORETTI, M.; FERETTI, D.; VILLARINI, M. A new approach to evaluating the toxicity and genotoxicity of disinfected drinking water. Water Research, Oxford, v. 38, n. 17, p. 3809-3819, 2004.

NURIZZO, C.; ANTONELLI, M.; PROFAIZER, M.; ROMELE, L. By-products in surface and reclaimed water disinfected with various agents. Desalination, Amsterdam, n. 176, n. 1/3, p. 241-253, 2005.

SOLVAY. PERÓXIDOS DO BRASIL LTDA. PROXITANE ${ }^{\circledR}$ 1512. Disponível em: <http:// www.peroxidos.com.br/docroot/h2o2/static_files/ attachments/10_paa_proxitane_0510_1512.pdf $>$. Acesso em: 19 ago. 2010.

RAJALA-MUSTONEN， R. L.; TOIVOLA, P. S.; HEINONEN-TANSKI, $\mathrm{H}$. Effect of peracetic acid and UV irradiation on the inactivation of coliphages in wastewater. Water Science and Technology, Oxford, v. 35, n. 11, p. 237-241, 1997.

ROSSI, S.; ANTONELLI, M.; MEZZANOFTE, V.; NARIZZO, C. Peracetic acid disinfection: a feasible alternative to wastewater chlorination. Water Environment Research, Alexandria, v. 79, n. 4, p. 341-350, 2007.

SANCHEZ-RUIZ， C.; MARTINEZ-ROYANO, S.; TEJERO-MONZON, I. An evaluation of the efficiency and impact of raw wastewater disinfection with peracetic acid prior to ocean discharge. Water Science and Technology, Oxford, v. 32, n. 7, p. 159-166, 1995.

SANTORO, D.; GEHR, R.; BARTRAND, T. A.; LIBERTI, L.; NOTARNICOLA, M.; DELL'ERBA, A.; FALSANISI, D.; HAAS, C. N. Wastewater disinfection by peracetic acid: assessment of models, for tracking residual measurements and inactivation. Water Environment Research, Alexandria, v. 79, n. 7, p. 775787, 2007.

SARTORI, L. Adequação da qualidade microbiológica de efluentes secundários de esgoto sanitário pela aplicação dos desinfetantes ozônio, permanganato de potássio e ácido peracético. 2004. 202 p. Tese (Dourado em Engenharia) - Escola de Engenharia de São Carlos, Universidade de São Paulo, São Carlos.

SHIKISHIMA, R. T. K.; RIBEIRO, W. B.; KUNIGK, L. Estudo da influência da salinidade e temperatura na cinética da decomposição de soluções de ácido peracético em água salina. In: CONGRESSO BRASILEIRO DE QUÍMICA, 48., 2008, Rio de Janeiro. Anais... Rio de Janeiro: CBQ, 2008.

SOUZA, J. B. Avaliação de métodos para desinfecção de água, empregando cloro, ácido peracético, ozônio e o processo de desinfecção combinado cloro/ozônio. 2006.
Tese (Doutorado em Hidráulica e Saneamento) Escola de Engenharia de São Carlos, Universidade de São Paulo, São Carlos.

VESCHETTI, E.; CUTILLI, D.; BONADONNA, L.; BRIANCESCO, R.; MARTINI, C.; CECCHINI, G.; ANASTASI, P.; OTTAVIANI, M. Pilot-plant comparative study of peracetic acid and sodium hypochlorite wastewater disinfection. Water Research, New York, v. 37, n. 1, p. 78-94, 2003.

VOGEL, A. I. Análise Química Quantitativa. Rio de Janeiro: LTC, 2008.

WAGNER, M.; BRUMELIS, D.; GEHR, R. Disinfection of Wastewater by Hydrogen Peroxide or Peracetic Acid: development off procedures for measurement of residual disinfectant and application to a Physicochemically treate municipal effluent. Water Environment Research, Alexandria, v. 74, n. 1, p. 33-50, 2002.

ZHAO, X.; CHENG, K.; HAO, J.; LIU, D. Preparation of Peracetic Acid from Hydrogen Peroxide, Part II: Kinetics for Spontaneous Decomposition of Peracetic Acid in the Liquid Phase. Journal of Molecular Catalysis A: Chemical, Amsterdam, v. 284, n. 1/2, p. 58-68, 2008.

ZHAO, X.; ZHANG, T.; ZHOU, Y.; LIU, D. Preparation of Peracetic Acid from Hydrogen Peroxide, Part I: Kinetics for Peracetic Acid Synthesis and Hydrolysis. Journal of Molecular Catalysis A: Chemical, Amsterdam, v. 271, n. 1/2, p. 246-252, 2007.

Recebido em 20 Julho 2011-Received on July 20, 2011.

Aceito em 16 Outubro, 2011 - Accepted on October 16, 2011. 